\title{
CONCEPT APPLICATION AS SOCIAL ACTIVITY
}

BARRY BARNES

Universidad de Edimburgo

\begin{abstract}
How do I explain the meaning of "regular", "wniform", "same", to enyoneP... -if a person has not yet got the concepts, I ahall teach him to wse the words by means of examples and by practice. -And when I do this $I$ do not communicate less to him than I know myself.
\end{abstract}

WITTOENSTEIN

I

"The 'rational-choice' approach to human behaviour is without doubt the best available model", so Jon Elster asserts, and I am willing to give him some cautious support (Elster, 1984, p. 112). ${ }^{1}$ But if human behaviour is for the most part the product of "rational" calculation, or else habitual behaviour subjected to continual monitoring and adjustment in the light of "rational" calculation, the problem of cultural diversity and its explanation is exacerbated. Anthropologists and sociologists may no longer have recourse to unlimited drafts of irrationality in order to explain why "they" differ from "us". The four great classes of others, ancestors, aliens, deviants and experts, must be assumed to be

I Certainly I would agree that all human beingw have similar basic calculative capabilities, that they are calculative and reflective as they act, and that they must be expected calculatively to appraine and evaluate any rules they choose to follow. On the other hand, human beings are not "rational" in the strongest sense of the term as used by economists: they are not "calculative and wholly self-interested". Nor can human beings be considered as independent atoms as "rationalchoice" theorists sometimes tend to do. 
so many rational agents, rational as we are rational, and the manifest variation in how they act and what they believe must be made intelligible on that basis. Other cultures sustain concepts and adhere to beliefs very different from our own. We must seek to show how it is possible for rational agents to do this. Deviant sub-cultures in our own society apply "our" concepts and interpret "our" beliefs very differently from us. We must seek to show how this too may be accomplished by rational agents. If a "rational-choice" approach to human behaviour is the best then so also is a relativist approach to the various forms of existing knowledge and culture, and to alternative collective strategies for the use and extension of a given body of knowledge and culture. ${ }^{2}$ In what follows I shall outline and defend an appropriately relativist approach. In particular, I shall argue that different collectively accepted ways of applying concepts, and hence of sustaining and extending a body of knowledge, should be viewed as alternative forms of rational social action. I shall make my case with particular emphasis upon concepts with empirical relevance. Accordingly I shall provide a picture of the growth of empirical knowledge which accords well with the conviction that the generality of human beings are rational agents.

\section{II}

Let me begin with an example, a hypothetical example but not an esoteric one; indeed I want my hypothetical situation to resemble as closely as possible our own everyday world, so that reflection upon the one may assist in understanding the other. Imagine, then, a society

I I shall use the term 'knowledge' to refer to a body of accepted belief and competence, or to belief and competence routinely identifiable as concordant with accepted standards. 
very much like our own-or rather my own. Imagine that it is English-speaking, and that for the most part activity and experience within it is much as it is for us. The way that we acquire terms or concepts, and use them, may serve as a guide to how they acquire and use their terms or concepts.

Thus, our imaginary society will have a term 'child', which is routinely sustained and passed on as a part of the culture and competently used by all or nearly all members much as we use that term. A term of this kind will not be taught by explicit definition or by the elaboration of lengthy descriptions and specifications. It will be largely taught, and learned, through processes of ostension: examples of children will be pointed out directly, and when sufficient cases have been pointed out, perhaps with other examples of things that clearly are not children, learners will find themselves able to use the term 'child' competently themselves. They will be able to project from a finite number of cases where 'child' is properly applied, to new cases where the designation 'child' is also appropriate and generally accepted. In our society, competence in the identification of children is largely although not entirely acquired through ostensive learning processes, and so similarly we may assume it to be in the society about to be considered.

Another term or concept which may be acquired in our own society largely through ostensive learning processes is 'fetus'. Let this also be the case in our hypothetical society, but note that fetuses are entities of a somewhat restricted incidence in that society and are only commonly encountered, say, in biology laboratories and agricultural research stations. Paradigm instances of fetuses are animal embryos at various stages of development: familiarity with these instances generates competent performance in the use of 'fetus'. 
Finally, and here we come to the crucial point of departure from our own experience, it must be accepted that our hypothetical society has not so far taken an interest in those entities which form and grow within the human womb, or at least such an interest has not so far had an effect at the level of language. The society is about to become interested in these entities. They are about to impinge upon its members as objects demanding attention and reflection. They are, therefore, about to be referred to and spoken of-or some of them are. What though will be said of them, and how will they be referred to, these things which hitherto existed beyond the realm of speech?

Clearly, many options are available to members of our hypothetical society as they seek to solve their little problem of nomenclature. A new name may be conferred on these "new" entities, or they may be assimilated into existing classes of things and referred to as fetuses, or (unborn) children, or as both, or some of the entities may be referred to in one way and some in another. Let us assume that in practice only two of all the conceivable linguistic strategies command any support, and opinion divides into those who speak of (unborn) children which are not fetuses and those who speak of fetuses which are not (unborn) children. If cultural uniformity is to be established one body of linguistic activity must give way in favour of the other. But is this a matter of agreement on a convention, or can it be established that one alternative is more sensible or more reasonable than the other? What case can be made for preferring one of the two alternatives?

Let us call an advocate for extending the use of 'fetus': a sophisticated advocate. This term, he will tell us, has traditionally been used as an empirical descriptive term. It has been learned directly by reference to 
accepted instances and applied to things clearly resembling those instances. In our advocate's view the newly observed entities present in the human womb clearly resemble existing instances of fetuses and indeed simply are fetuses.

Our advocate will acknowledge that these new entities are not identical to existing examples of fetuses, but this, he is bound to point out, is no reason for withholding the appellation and coining a new term instead. Every existing fetus is discernibly different from every other, yet remains a fetus. If new terms were to be coined every time an entity appeared discernibly different from existing entities then there would be as many terms as entities, and linguistic communication would disintegrate. Fetuses need not be identical to each other; they must merely resemble each other.

But do not these new entities also resemble existing instances of children? To some extent they do, our advocate may well concede, just as they resemble many other structured entities to some extent, but the strongest degree of resemblance as far as he is concerned is with fetuses, and on this basis they should be called fetuses. And if they are to be fetuses they cannot also be children, since the beliefs and the practices surrounding existing instances of these two terms are incompatible and contradictory. It is necessary to label on the basis of maximal resemblance and to accept that the use of one label precludes the use of others. ${ }^{3}$

This case has I think considerable power and persuasiveness. But it is not sufficiently powerful. Merely by switching the terms 'child' and 'fetus' in what has just been said an equal and opposite case can be made on behalf of the alternative development of usage. If

3 Not of all other labels, needless to say: a fetus may presumably also be referred to as an embryo or an organirm. 
concept application proceeds on the basis of maximal perceived resemblance with ostensively given instances, and if people differ in what they take to be maximal resemblance, then usage is liable to diverge, even in a society of rational agents. There is no metric for resemblance: where an entity is discernibly the same as another or others, but at the same time discernibly different from it or them, there is no absolute scale for measuring sameness and difference and producing a magnitude of resemblance. If one set of agents thinks it is more like a fetus than a child and another thinks it is more like a child than a fetus, where both terms have been learned by ostension, then there is no way of resolving their differences by reasoned argument: what we have here is a difference in perceptually based intuitions, not something at the level of inference and conscious ratiocination.

Needless to say, agents themselves may fail to recognize that their differences are not merely matters of error or irrationality on one side, and their attempts to resolve their differences may very well have the form of reasoned argumentation. There would be no cause for surprise if folk-theories of reference were involved in the dialogue between the opposed parties, although it would perhaps be a little surprising if their use had the effect of altering existing convictions. Do not we take it as part of the implicit definition of a child that it is a viable human being? No, comes the reply, any convictions we have held about the viability of children have been a posteriori, and now that we have encountered non-viable children such convictions turn out to be false. Have we not always taken fetuses to be embryonic stages of animals? No, comes the reply, merely because existing instances have always been animal embryos does not imply that they have so to be; and in 
any case what warrant is there for assuming that human fetuses are not animals, or even that human beings generally are not?

Notice here an interesting implication as far as the truth and falsity of empirical assertions are concerned. Where such assertions use terms learned wholly by ostension it would seem that their truth or falsity must be indeterminate, since the future application of such terms is not fixed in advance. Suppose there is a generally accepted empirical belief, "children are viable". If entities within the womb subsequently are to be identified as children then this assertion proves false, whereas if they are identified as fetuses, not children, the assertion may yet still be true. But whether one identification or the other eventually comes to be made is not wholly dependent on the existing usage of the two ostensively learned terms, the rational comparison of their "meanings", the characteristics of the entities about to be identified, or any combination of these things. Either identification may be made and collectively accepted without doing violence to reason, to the promptings of perception, or to existing usage. And which identification eventually is made will be a contingent, empirical matter, not deducible in advance even for a society of rational agents.

The ex post facto rationalization of ostensively-based linguistic practice may proceed other than by the citation of alleged defining descriptions and the construction of "the rules" allegedly implicit in existing usage. It is possible to invoke more subtle features of the way in which concepts are generally used. There is, for example, our apparent respect for spatio-temporal continuity. Consider how a given human being remains the same human being throughout his life, young and old, sick and healthy. His appearence may change out of all 
recognition. Every component of a distinguishing empirical description valid in his youth may become invalid at a later date. And yet, once called John Smith he remains John Smith. The members of his community will successively re-identify him over and over again as John Smith, even as his features change; they will keep their identification in being by speech act after speech act, bearing in on the specific John Smith as an entity with spatio-temporal continuity. In their linguistic practice there is, it might be said, an implicit commitment to such continuity as the basis for concept application. Thus it might be argued that since entities within the womb are spatio-temporally continuous with those viable human beings called children, the entities themselves are of the same nature as children and are thus themselves children. Unfortunately, the reply will come that spatio-temporal continuity is a strictly optional basis for concept application, and that it cannot be assumed to be implicitly present as a rule which we are unbeknowingly obliged to follow. A caterpillar is not a butterfly, spatio-temporal continuity notwithstanding. Ice is not water. John Smith's corpse is not John Smith, nor is his severed hair a part of him, or the meal he is just about to eat. Spatio-temporal continuity may bear upon the application of concepts just as perceived resemblances may, but it cannot determine the correct application of ostensively learned concepts any more than perceived resemblance can. ${ }^{4}$

Where factions within a community persist in developing existing usage in opposed directions each may not only attempt to persuade the other into conformity,

\footnotetext{
- I have argued in detail elsewhere that no specific theory of reference or extension can predict proper usage and both ${ }^{\alpha}$ description theory" and "realist theory", the two most developed existing theories, simply fasten upon selective aspects of the actual unfolding of proper usage. See Barnes (1982a).
} 
but also strive to reinforce and legitimate its own practice to its members' satisfaction, and thus make that practice yet more resistant to the blandishments of the other side. A commonly used resource here is the language of essentialism, which can be employed to justify a strategy of concept application without standing on the shaky ground of resemblances and manifest appearance. Thus, it might be, in our imaginary society, that references to the unborn child are justified in essentialist terms. Never mind appearances, it may be said, unborn children are of the same nature as other children because they share the same invisible essence. Well before the unborn child is even visible as an entity, an invisible essence has passed into it and taken up abode within it. That essence, the human soul perhaps, will remain in the material body of the child as it grows and will only depart at the point of death. It is the underlying presence of the essence which justifies extending the concept 'child' to cover entities within the womb.

Use of the language of essences serves to institutionalize a specific strategy of concept application here, and clearly serves notice that references to appearances and perceived resemblance will no longer be allowed as challenges to existing practice. But it should not be imagined that this is "the" point of essentialism, or the only reason for having recourse to essences. Essences may be invoked to do all kinds of work. They have, for example, a particular convenience in situations where there is high division of intellectual labour-where differentiated bodies of knowledge must be combined together, or experts and lay-persons must establish a modusvivendi. ${ }^{5}$ Thus, it may be asked, given that the soul is an invisible essence, how it is known to exist and how

s Putnam's philosophical work has a particular value because of its recognition of the relationship between social organization and seman- 
the time of its arrival within its material substrate is ascertained. And the answer may be given that this has just been ascertained by "the experts", the priests and theologians skilled in the interpretation of sacred texts and privy to forms of knowledge transcending observation. Essences may relate to phenomena rather as experts relate to lay-persons. But, needless to say, if there is any disposition to deny the authority of expertise in situations of this kind, then the existence of essences is likely to be denied also, and indubitably will be denied where lay references to essences are no more than a device for directing attention to expert pronouncements.

Finally, let us consider the fact that where alternative strategies of concept application are found to emerge and persist alternative collective goals and interests tend also to be found, and to be correlated with the opposed linguistic strategies. In our own society, people who are actively opposed to abortion insistently refer to the unborn child within the womb, and emphasise as strongly as they are able the extent of the empirical analogy between "unborn" and "normal" children. No doubt they believe, probably correctly, that the more an entity is perceived to resemble a child the more readily will it be granted the rights enjoyed by children. For the same reason, other groups punctiliously refer to the fetus in the human womb, and invite us to consider the earlier rather than the later stages of its development. These groups may be involved in the promotion of abortion as social policy, or they may have an eye to the potential therapeutic value of human fetal tissue, for example in relation to Parkinson's disease or Altzeimer's disease.

tics. His (1975) discussion of division of intellectual labour is particularly relevant in the present context. 
Our customary attitude to contingent human goals and interests is that they are potential causes of distortion and bias in the generation of empirical knowledge: we contrast "disinterested" and "biased" descriptions, and thereby signify also our trust in the former and suspicion of the latter. But it would seem clear from the present example that interests may affect concept application and the growth of knowledge without generating biases or distortions in that knowledge. Suppose that in our hypothetical society the two opposed strategies of concept application I have described grew up and persisted as the favoured modes of speech of abortionists and anti-abortionists. Suppose, even, that supporters and opponents of abortion were moved wholly by mean calculations of profit and loss, and that when they spoke of the resemblances between things, and of some resemblances being stronger than others, they merely rationalized a strategy of concept application favoured purely out of cynical expediency. Even in this case it is difficult to say in what sense concept application has been biased and knowledge distorted. For we have no available conception of unbiased concept application and undistorted knowledge. All we have are alternative rationally defensible strategies of concept application, and members of a community obliged to employ one or another as a basis for communication and a backdrop to social practice. And all that interests do is to prompt specific choices between rationally defensible alternatives. There is no best representation of reality to which disinterested agents turn, and away from which biased agents turn. There are alternative strategies for representing aspects of reality which stand formally on a par with each other, and between which agents choose according to how their interests are favoured thereby. Interests are constitutively involved in the processes of 
concept application by which the knowledge of a community persists and grows. And when they are constitutively involved in this way they help us to explain how knowledge or accepted belief has grown, but not directly to evaluate the knowledge or belief in question. This is the case whether the interests in question are technical, the kinds of pragmatic interest which scientists legitimately seek to further, or moral or political. Interests may largely determine whether children or fetuses are said to grow within the human womb, but not in the sense of determining whether truth triumphs, or error.

\section{III}

It will be clear, I hope, that most of what has been said of concept application in the above example is not peculiar to the example but could be said in relation to any system of ostensively learned concepts. Let me summarize some of the major points which have emerged and present them as general conclusions.

1. The future use of ostensively learned concepts is openended and underdetermined by existing use or existing "meaning". Ostension shows precedents for the use of terms and allows usage to proceed on the basis of resemblance with precedents. This does in practice allow concept application to proceed as collective activity. But the resemblance relation is problematic: concept application may move in alternative equally defensible directions on the basis of resemblance.

2. Because ostensively-learned concepts lack extensions, or pre-determined domains of application, assertions involving them cannot be regarded as determinately true or false. The future instances to which such assertions will eventually apply cannot be known, or known of, ahead of future use.

3. Given that there is always a collective interest in lin- 
guistic uniformity there will always be a tendency for language users themselves to impute inherent powers or meanings to ostensively learned concepts, and to identify more constraints upon how they may properly be used than will be apparent to an external observer. Options in the development of usage will be liable to be made out as necessities.

4. One interesting strategy for the ex post facto rationalization of specific ways of using ostensively learned concepts is the imputation of underlying essences. In some cases, the imputation of essences may be treated as a device for imputing authority to a particular selected strategy of concept application.

5. A collective preference for one strategy of concept application over another is a matter of contingent choice where concepts are ostensively learned. How concepts are actually employed is a matter for empirical investigation; like any other social activity the application of a concept must be understood as an empirical occurrence with causal antecedents in the setting in which it occurs. Frequently, perhaps invariably, a specific strategy of concept application will be selected because of its relevance to the interests of language users. When this occurs the interests in question will count amongst the contingencies which account for the extension of usage and the growth of knowledge in the relevant society: the interests will be constitutively involved in the process of knowledge generation, just as perception and inference are constitutively involved.

With these five points we have a finitist account of the use and application of ostensively learned concepts. Since the emphasis has been on the collective application of concepts and the development of proper usage, 
and since such concept application has been identified as a form of social activity, it seems sensible to speak of sociological finitism here. Sociological finitism is offered as the most satisfactory available account of the collective use of ostensively learned concepts.

What we should now do is remind ourselves of the scope of the account, if indeed it is correct. Ostension is simply the process by which we connect language with the physical environment in which we exist. If a body of knowledge has any empirical significance then the processes of ostension will have been involved in its acquisition. And the open-ended character of concept application deriving from the indefiniteness of ostension and the problematic nature of the resemblance relation will appertain, and will indeed be ineradicable and irremediable. Accordingly, sociological finitism if it is correct at all will be the correct account of the use and application of all empirically applicable concepts, and of the development of all bodies of empirical knowledge without exception. ${ }^{6}$

In our hypothetical example the application of existing concepts to a "new" entity was discussed. But the intention was, needless to say, to offer a paradigm instance which nicely exemplifies what is involved in any application of any term to any thing in any circumstances. The application of 'fetus' to a non-standard example was discussed. But the "routine" application of the term to a "normal" unproblematic case has been equally well described. The "normal" next case will differ from existing cases just as the non-standard case does: the problem of resemblance will arise, and all the rest of the argument will follow in consequence. The example elicits the characteristics of the routine appli-

- If one takes a broadly empiricist view of logic and mathematics one might simply speak of knowledge generally here. 
cation of concepts. It indicates how the routine identification of the next fetus should be thought of, or the next cat, or the next anticyclone, or the next schizophrenic, or the next electron.

The application of concepts to things is open ended. Such concept application must be studied and understood as social activity. Every act of concept application is an empirical phenomenon, intelligible only in terms of the contingent determinants bearing upon it in the context wherein it occurs; so is every act of acceptance of such an application within a collectivity. The growth of empirical knowledge is, formally speaking, the product of a great number of such acts. We must think of whole communities applying terms in act after act, and thereby clustering particulars together under terms. All these acts will be the products of contingent determination. Such determination may be unsystematic, reflecting many contingencies and diverse interests, but more commonly it will involve the systematic and continuous operation of specific interests and thereby generate a highly uniform linguistic practice based on a recognizably shared body of knowledge. Thus we have our medical knowledge of the human fetus, and our physical knowledge of the electron, both established in specific sites and maintained as and by the social activity of specific communities. ${ }^{7}$

\section{IV}

What criticisms should a finitist account of concept application be prepared to face? Certainly, it must be prepared to defend its premises and inferences, to demonstrate its formal reputability. But it also stands as an empirical account of how concepts are applied and how

The brief remarks in this paragraph are elaborated and illutrated in Barnes (1982b, section 5.3). 
their users establish that they are properly applied. Although it may be said to be a philosophical theory in the sense that theories of reference and extensional accounts of semantics are philosophical theories, it is primarily a sociological theory of an aspect of social behaviour. Hence it must show itself to be compatible with empirical evidence, that is, with observations of how people actually in practice apply concepts and agree on their proper application. And indeed it is empirically-based criticisms which seem to me the most challenging and profound.

As far as the strength of the argument is concerned the key issues would seem to be the alleged open-endedness of concept application, the matter of whether and to what extent it is remediable, and, if so, how far such remedies might restrict the scope of a finitist account. Many interesting problems arise in the discussion of these matters, but I shall largely pass over them here since they are very satisfactorily treated in other contributions. The indefiniteness of ostension and the problematic character of notions of similarity and resemblance are close to counting as accepted findings in philosophy, having been extensively considered by some of the seminal writers in that field. ${ }^{8}$ And the difficulties encountered by all attempts to "close-down" the open-endedness of ostensively-learned concepts are also well-known. It will not do, for example, to impose verbal definitions upon our concepts and require that future usage proceeds in strict conformity with the definitions. For although we may replace references to ostended instances of a term with references to its verbal definition, the question then arises of the proper use of the terms

- The point is made many times in Wittgenttein, Quine, Goodman, Hesse, Kuhn, and, needless to say, many others texts. For a sociological treatment see Barnes (1984). 
within the definition itself. And this presents us with the choice either of giving verbal definitions of the terms in our definition, or of resorting to ostension to indicate their proper use. The first option initiates a potentially endless regress. The second option may be turned to at any point to terminate the regress, but such a resort to ostension merely regenerates the initial problem. There never comes a point where resort to ostension allows us to point to perceptibly identical paradigm examples, and to define the instances of a concept as those things perceptibly identical to the paradigm examples. There is no such thing as exhaustive description.

Thus we may indeed adopt definitions, say, for 'fetus', or 'child', but as far as our present interests are concerned they will avail us nothing. If our definitions include terms of empirical significance, they merely allow us the choice of where we will confront the problem of resemblance and the indefiniteness of ostension: references to the non-viability of a fetus allow us to worry about what counts as non-viable instead of what counts as a fetus. If our definitions include no terms of empirical significance we shall have no guidance at all for the correct application of our concepts, and will have them available only for armchair chit-chat: reference to the presence of a soul in a child, where no sign of that presence is given ostensively, tells us nothing at all about what entities are children and what not. In a nutshell: the open-endedness of concept application cannot be eliminated, nor can its consequences be mitigated or restricted in scope.

Let me turn finally to the extent to which finitism is compatible with our everyday experience of applying and using concepts. Here the intuitive feeling may be that although I have described some cases of concept application adequately, notably the difficult or prob- 
lematic cases, at the edge of usage as it were, I have failed to capture what is involved in collective routine usage. Normal cases of concept application, even of the proper collective application of concepts, do not involve difficulties, the need for reflection and justification, the development of conventions. They do not seem to have the character of contingent judgments at all. They have an automatic character. We see a cat, and even as we see it we all think "a cat", without reflection, without hesitation, without negotiation, almost, we might say, mechanically.

This description of much mundane, routine concept application is, I agree, correct and convincing. But it is important to be clear what it amounts to. It states that when we apply concepts we frequently do so unreflectively and automatically, and that in doing so we usually find ourselves in agreement with other users of our language. These are empirical facts about ourselves. They merit recognition. But they do not entitle us to speak of underlying meanings guiding our use of language, or of underlying rules being followed, or of the inherent similarities between things inducing us to speak of them as we do. When we identify, say, a cat, we do so without awareness of any of these things, where normal routine usage is concerned: we apply our concept of cat "blindly", as Wittgenstein puts it $(1953, \mathrm{I}$, 219). It is crucial that we do not over-rationalize such actions. Probably they have a great deal to do with our human perceptual apparatus, with memory, and with habits of speech, but they have no clear connection at all with reasoning, or with the analysis and interpretation of formulated rules or meanings. ${ }^{9}$ And thus they are not

- Wittgenatein seems to have been averse to any kind of theorising about our routine application of concepts or our routine application of rules. Certainly theories which attribute intrinsic powere to con- 
in themselves definitive of proper usage, as if what is done automatically is thereby done correctly. There is a connection between what is automatically done and what is correctly done, but not an equivalence.

Note first that the automatic response of a single individual cannot begin to serve as the basis for fixing correct usage. An individual may make a mistake, or he may have been mistakenly taught, or he may be idiosyncratic in his perceptions - through colour-blindness, for example, or tinnitus.

The automatic response of the individual is subject to correction through comparison with the automatic responses of everyone else, given that those responses largely agree. A massive congruity in the "blind" application of concepts allows "correct usage" to be spoken of and "mistaken usage" to be identified and corrected with regard to a given concept. Indeed it is only because there are cases where agreement in unreflective linguistic practice exists that it is possible to discriminate between correct and incorrect usage at all. ${ }^{10}$ Nor is this merely an assertion that in using our language we must all share the same perceptual machinery.

Consider our hypothetical society again, with its concepts 'fetus' and 'child'. Imagine that the first dèsignations of entities within the human womb were designations of unborn children. Suppose everybody unhesitatingly, automatically, recognized these entities as children, as a matter of course. This is perfectly conceivable, empirically. We need only imagine a devout society, intensely conscious of the difference between

cepts or rules are effectively criticised in his work. But I see no basic objection to sociological, paychological or physiological theories of the machinery of perception and recognition.

10 Again the insight is Wittgenatein's. An interesting commentary is provided in Kripke (1982). 
the human and the non-human, intensely respectful of anything with the vaguest affinity with humankind, intensely aware of the shape and form and appearance of human individuals. In such a society the nature of the unborn child, and its total lack of affinity with or resemblance to fetuses, might be immediately obvious - merely a matter of looking, as it were. Yet this obviousness would not simply be a consequence of the inborn mechanism of perception, or of how 'fetus' and 'child' had previously been used. It would be the consequence of the entire way of living in the society. Keep basic perceptual machinery the same; keep previous usage of 'fetus' and 'child' the same; only alter the broader pattern of living; and the routine extension of usage of these two terms might radically change. In a rampantly scientistic society, what were obviously and self-evidently unborn children might perhaps have been identified as obviously and self-evidently fetuses. The automatic extension of usage might well have proceed in a different direction. Thus, if we are inclined to talk of a "machinery" involved in the perception and recognition of things and capable of automatic operation, we must allow that it is programmable machinery which may operate differently in different social contexts. And in so far as people are agreed in their automatic unreflective application of concepts it must be not only because of a shared perceptual machinery, but because of shared programmes as well.

Note how this brief discussion has re-established the general relevance of the finitist account of concept application set out earlier. The future use of ostensively learned concepts, even when they are applied blindly and automatically, is still not determined by existing use or existing meaning, for the automatic application of concepts may vary with context even where previous 
use and existing meaning do not. And where there is such possible variability in future applications of concepts there can be no truth or falsity attributable to assertions in which they presently appear.

Let me return to the matter of the relationship between what is automatically done and what is correctly done. I have said that it is the existence of agreement in what is automatically done which allows talk of correct and incorrect usage. I now wish to show that what is automatically done does not determine what is correctly done.

An erroneous way of understanding a finitist account of concept application might proceed as follows. First: concept application is formally speaking open-ended because of the problematic character of the relation of resemblance. Second: we nonetheless agree in practice upon what resembles what in many specific cases, because of the operation of the underlying machinery of perception and memory; in these cases agreement in practice directly fixes proper usage. Finally: where we do not agree in our practice in a specific case we must seek to develop usage by convention, and make contingent judgments as to which conventions will best suit us, given our interests.

The error lies in the second point, which forgets that even when an entire community finds itself at one in its routine practice, in its normal ways of applying concepts on the basis of perceptual prompting, it may nonetheless hold itself in error. Nothing in the realm of social activity is unrevisable. Nor is this a small point empirically. Collective habits of perception and spontaneous inclinations in the application of concepts are constantly being overridden as agents sustain a reasonably unified, coherent, pragmatically valuable pattern of culture. Such overriding is essential: there is no way 
in which a single coherent pattern can be sustained purely as the habits of separate individuals, even carefully trained and pre-programmed individuals. ${ }^{11}$ Thus, in everyday life standard collectively uniform perceptions may be discounted or reflectively modified, as for example when we achieve a simple coherence between visual and tactile perception by talk of optical illusions. Such perceptions may similarly be set aside as incorrect in deference to expertise: we may perhaps identify gold and diamonds routinely, blindly, without hesitation, yet if we seek to purchase some we may well set aside such identifications in favour of expert advice. Similarly, experts themselves may make a distinction between collective routine usage and proper usage. Medical practitioners distinguish the living from the dead routinely, as a matter of course; ostensively learned instances and similarly learned skills and procedures suffice as the basis for agreement in practice. Yet there is nothing contradictory in the fact that these practitioners question their practice even as they use it, nor would it be out of the question for them to decide that it was an incorrect practice and always had been. ${ }^{12}$ Scientific

11 Thus, even if individuals in a society were to extend usage of a term from a standard example only when they could perceive no difference at all between one intance and the next, perception would not be sufficiently rigid at the individual level to sustain a form of culture. Notice that if we take any two different colours we can alway construct any number of intermediate shades so that any two "adjacent" shades are indistinguishable to the human eye. Perceived "uame-colour" identifications could move automatically and routinely from one end to the other of such a continuum if not subjected to some ex post facto collective discipline.

12 Needless to say the problem of how to determine death is a serious and absorbing one for medical practitioners, even though they apparently do it as a matter of course all the time. An intriguing recent incident is worth mention here. Every year some hundreds of "fatalities" in far-east Asia have been caused by imbibing a poisonou: substance from inadequately prepared puffer-fish. Apparently, these fiah are such a delicacy that gourmets willingly take the risk of eat- 
researchers agree to a great extent in routine observational and experimental practice, but they readily set aside the indications of specific parts of that practice at specific times in order to sustain the coherence of the whole, and they may even discard whole areas of practice as incorrect and thereby identify any number of earlier routine acts of concept application as the misuse of those concepts. ${ }^{13}$

It follows that what the members of a community are able to do blindly and automatically, in agreement with one another, is not necessarily definitive, even in their eyes, of what they do correctly, where the application of concepts is concerned. The existence of some degree of automatic agreement is essential, since without it the members of a community would be wholly unable to communicate and exchange information. But any part

ing them. There has been a small but persistent movement of bodies from the restaurant to the crematorium. Recently, however, it has transpired that the secretions of the puffor-fish are used by voodoo doctors in Haiti to induce a state of catalepay. The active ingredient is evidently related to chemicals which cause animal hibernation, and is capable of lowering bodily metabolism to well-nigh undetectable levels whilst maintaining full consciousness.

13 For a discussion of the role of coherence conditions in science see Hesse (1974), Bloor (1984). The value and utility of the vocabulary of realism in the achievement of coherence is everywhere apparent: it does sterling work in disposing of unwelcome appearances and in ordering and aligning acceptable ones, especially in the context of scientific research where a shared realint strategy is usually essential and explicit.

In this conection, note also the massive disjunction between a routine act of perception and/or recognition and that which comes to be called a "acientific observation". Consider recent observations uning particle accelerators, designed to identify and atudy the $\boldsymbol{w}$ particle and the $z$ particle. No individual can make these observations. In principle they are the observations of an ordered and differentiated collectivity acting as one. Their social organization and correct interaction is as crucial to these observations as the organization and correct interaction of the parts of the eye are to the individual observation of a cat. The standard usage of the term 'observation' has extended and developed in interesting ways from the atandard instances traditionally used to illustrate its proper use. 
of agreed practice may nonetheless be made the object of reflective evaluation (wherein much of the rest of agreed linguistic practice must temporarily be taken for granted). What is automatically done in agreement still has to be accepted as being correctly done in agreement, and this acceptance is a contingent matter. Where people reject the correctness of standard routine practice contingency is manifest in overt judgments and decisions. Where people accept routine practice this is not the case. It remains true to say that in such acceptance people are doing something which they do not have to do: they are permitting what is routine to count as what is correct.

Let me conclude then by risking a general statement about the way in which rational agents in all cultures apply the concepts they have learned, and thereby sustain and extend the body of knowledge they have inherited as a viable account of the world. Through explicit training and through the imitation of others such agents will find themselves able to apply concepts blindly, without thought or reflection: when an object is encountered a specific term for the object will immediately come to mind. This initial designation is not sacrosanct. But every agent will take it as a matter of course that every other member of his society will also make the same initial response, that what comes naturally and automatically to him will come naturally and automatically to everyone trained like him. ${ }^{14}$ The initial response is accordingly the only "prominent solution" to the problem of linguistic coordination (Schelling, 1960; Lewis, 1969). In all contexts where agreement itself is more

14 Needless to say far more is involved in the assumption of a common perspective than this remark uggests. The basis of the assumption, the grounds for it, the explanation of why and how it is made, the question of whether it is optional or universal in a society, are all matters of great sociological interest. See, for example, Schutz (1962). 
important than the specific form that agreement takes this solution will rapidly be adopted; and indeed the practice of moving to this solution will itself become a matter of routine. A principle of maximum cognitive laziness will appertain: other things being equal, count what is routine as what is correct. But if other things are not equal, if the extra work is pragmatically justified, if a specific kind of agreement is particularly valuable, then automatic tendencies may be overridden. New patterns of coordinated linguistic practice may be established, just as they have to be when there is no existing agreement in routine practice in the first place.

The machinery involved in the perception and recognition of things hums along undisturbed much of the time. For the individuals in a given society it usually hums along in unison; indeed it has so to do for a society to exist. The possibility of society depends upon a certain blind conformity in our perception, understanding and judgment, in our initial responses to things. But the machinery of perception and recognition is nonetheless subordinate to human reflection and calculation. The basis of sociability, and thus of humanity, lies in our shared tendencies to automatism, but its actual achievement lies in the calculative exploitation of these tendencies.

\section{BIBLIOGRAPHY}

Barnes, B. (1982a), "On the Extensions of Concepts and the Growth of Knowledge", Sociological Review, 30, 1, 23-44.

- (1982b), T. S. Kuhn and Social Science, Macmillan,London.

- (1984), "The Conventional Component in Knowledge and Cognition", in N. Stehr and V. Meja (eds.), Society and Knowledge, Transaction Books, London.

Bloor, D. (1984), “Durkheim and Mauss Revisited: Classification 
and the Sociology of Knowledgen, in N. Stehr and V. Meja (eds.), op. cit.

Elster, J. (1984), Ulyoses and the Sirens, Cambridge University Press, Cambridge.

Hesse, M. B. (1974), The Structure of Scientific Inference, Macmillan, London.

Kripke, S. A. (1982), Wittgenste in on Rules and Private Language, Blockwell, Oxford.

Lewis, R. K. (1969), Convention, Harvard University Press, Cambridge, Mass.

Putnam, H. (1975), “The Meaning of 'Meaning' ", Mind, Language and Reality, Cambridge University Press, Cambridge.

Schelling, T. C. (1960), The Strategy of Conflict, Harvard University Press, Cambridge, Mass.

Schutz, A. (1962), Studies in Social Theory, Nijhoff, The Hague.

Wittgenstein, L. (1958), Philosophical Investigations, Blackwell, Oxford. 


\section{RESUMEN}

En este ensayo se parte del problema de la diversidad cultural y de su explicación. Las diversas culturas, y diversos grupos dentro de cierta cultura, deben verse como racionales, so pena de caer en un inadmisible etnocentrismo, aunque sostengan creencias muy diferentes entre sf. Se plantean entonces dos problemas: icómo hacer inteligibles las variaciones de las acciones y las creencias de diferentes agentes racionales en culturas distintas? ¿Cómo es posible que agentes racionales interpreten nuestras creencias y conceptos de una manera muy diferente a como nosotros lo hacemos? El autor propone y defiende un enfoque relativista. Sostiene que hay diferentes maneras, colectivamente aceptadas, de aplicar conceptos y de sostener y extender cierto cuerpo de conocimientos, y que todas ellas deben ser aceptadas como formas alternativas de acción social racional. Presenta una concepción finitista sociológica del uso y la aplicación de conceptos aprendidos ostensivamente. Se le llama sociológica puesto que pone el énfasis en la aplicación colectiva de conceptos y en el desarrollo de su correcta utilización, y tal aplicación se identifica como una forma de actividad social.

Los aspectos principales de esta concepción pueden resumirse de la siguiente manera:

1. La utilisación futura de los conceptos aprendidos por ostensión es abierta y subdeterminada por el uso existente o por el asignificado" existente. La ostensión muestra antecedentes para la utilización de los términos y permite que siga dicha utilización con base en la semejanza con los antecedentes. En la práctica, esto permite que la aplicación de conceptos sea una actividad colectiva. Pero la relación de semejanza es problemática: la aplicación de conceptos puede moverse en direcciones alternativas igualmente defendibles sobre la base de semejanzas.

2. Debido a que los conceptos aprendidos por ostensión carecen de extensiones, o de dominios predeterminados de aplicación, las afirmaciones que los incluyen no pueden considerarse determinantemente verdaderas o. falsas. No pueden conocerse los casos 
futuros a los que eventualmente se aplicarán dichas afirmaciones antes de su utilización.

3. Puesto que siempre hay un interés colectivo en la uniformidad lingǘrtica, siempre habrá la tendencia de que los mismos usuarios del lenguaje atribuyan poderes o significados inherentes a los conceptos aprendidos ostensivamente e identifiquen más restricciones (acerca de cómo deben usarse éstos correctamente) de las que verá el observador externo. Las opciones en el desarrollo de la utilización estarán expuestas a ser vistas como necesidades.

4. Una estrategia interesante para la racionalización ex post facto de maneras específicas de usar conceptos aprendidos por ostensión, es la atribución de esencias subyacentes. En algunos casos, la atribución de esencias puede considerarse un mecanismo para atribuir autoridad a una estrategia seleccionada particular de aplicación de conceptos.

5. La preferencia colectiva por una estrategia de aplicación de conceptos sobre otra es cuestión de elección contingente, cuando los conceptos son aprendidos ostensivamente. El saber c6mo se utilizan de hecho los conceptos es asunto de la investigación empírica; la aplicación de un concepto debe entenderse, como cualquier otra actividad social, como una ocurrencia empírica con antecedentes causales en el ámbito en el que ocurre. Con frecuencia, tal vez invariablemente, se seleccionará una estrategia específica de la aplicación de conceptos por su relevancia para los intereses de los usuarios del lenguaje. Cuando esto ocurre, los intereses de que se trate estarán entre las contingencias que dan cuenta de la extensión de la utilización y del crecimiento del conocimiento en la sociedad relevante: los intereses estarán constitutivamente involucrados en el proceso de generación de conocimiento, al igual que están constitutivamente involucradas la percepción y la inferencia. 